\title{
Compassion for Animals
}

\author{
Nancy E. Snow \\ Marquette University
}

Editors' Note: The following discussion by Professors Snow and Russow was presented at the Central Division meeting of the Society for the Study of Ethics and Animals, held in Louisville, Kentucky, April, 1992.

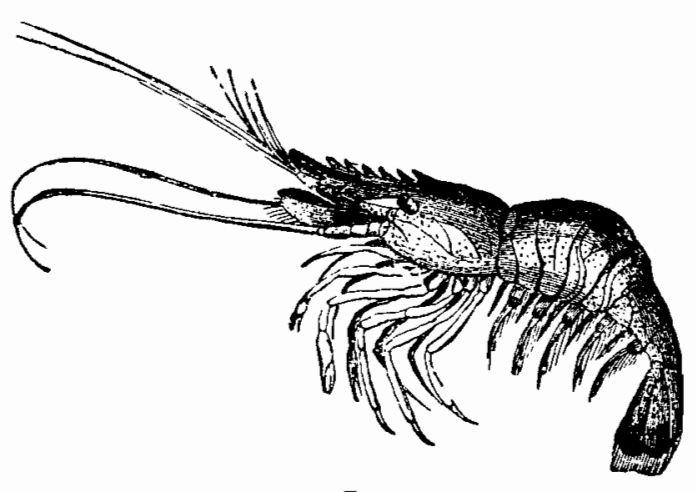

I

My thesis is that it can be, and frequently is, rational for humans to feel compassion for nonhuman animals. Compassion for animals can be explained by examining several modes of connection between humans and other animals. The connections encompass modes of identification between humans and other animals, for example: imaginative reconstructions of their subjective experiences, beliefs about humans and other animals, including beliefs about similarities between species, other emotions toward animals, such as kinship feelings, and outlooks or ways of life that reflect value judgments about and attitudes toward nonhuman animals. To feel compassion for animals is to be connected with them in an especially complex way. The challenge of this essay is to comprehend this connection.

Two competing accounts of compassion have emerged in recent philosophical literature. ${ }^{1}$ Both rely on a core definition of compassion as an intense emotional response to the misfortune of another, which includes suffering with the other, and concern for the other's good. This concern is frequently expressed in benevolent other-regarding thoughts, desires, and

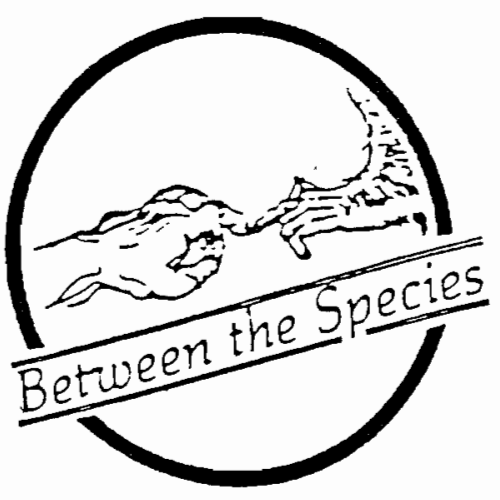

actions. ${ }^{2}$ Both models maintain that compassion is made possible by the ability of the one who feels compassion (source) to identify with the plight of the individual for whom compassion is felt (target). ${ }^{3}$ They diverge in their analyses of how identification is achieved. One account, advanced separately by Lawrence A. Blum and Adrian M. S. Piper, contends that imaginative reconstruction of the other's subjective experiences is necessary for identification. ${ }^{4}$ The alternative, which I develop, denies that imagination is required for identification, but admits that it can play a facilitating role. That the source has a particular set of beliefs, including beliefs about the target's vulnerability and its role in occasioning the target's plight, as well as beliefs about the source's similar vulnerability and consequent liability to misfortune, can suffice for identification. ${ }^{5}$

Examining compassion for nonhuman animals not only reveals the limitations of the imagination-based account; it also underscores some advantages of the belief-based model. The weaknesses of the Blum/Piper view are discussed in part II. The contention of part III is that the original version of the belief-based model can be amended to explain how human compassion for other animals is possible, appropriate, and rational. Part IV concludes by briefly sketching conditions under which compassion is misnamed, misplaced, or irrational.

A preliminary comment. Both accounts presuppose a cognitively complex conception of emotion, according

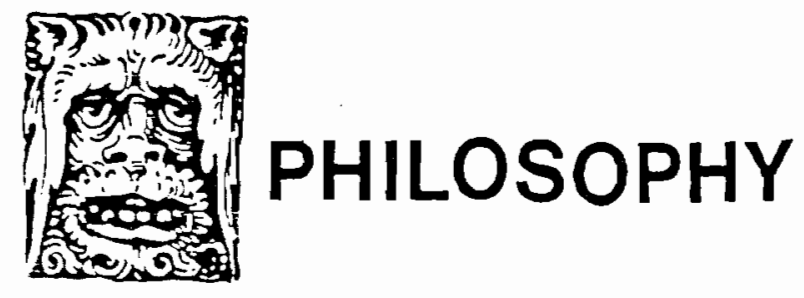


to which both belief and affect are essential components. The conception's main features are:

1) At least some emotions are composites of beliefs and feelings;

2) There are beliefs that characteristically accompany each kind of emotion that distinguish it from every other kind; and

3) Some of these beliefs are about the target of the emotion. ${ }^{6}$

Consequently, the physiological states experienced by a person who feels emotion cannot be identified as a particular emotion, for example, compassion, pity, or anger, without reference to that person's beliefs.

\section{II}

Neither Blum nor Piper claims to explain compassion for nonhuman animals, but, instead, both restrict their accounts to compassion between human persons. This restriction is related to their belief that imaginative identification with the other's condition is required for compassion. Blum maintains that "failure of imagination is typically not a purely intellectual or cognitive failure; for it can itself be part of a more general failure to regard the other as fully human, or to take that humanity sufficiently seriously" and that "the limits of a person's capacities for imaginative reconstruction set limits on her capacity for compassion."7 For Piper, compassion requires "an application of modal imagination to a particular kind of imaginative object, namely, a human subject, and to a particular quality of that kind of object, namely, her inner states." imagine what it would be like for himself or herself to be in the other's condition is not, for the Blum/Piper account, sufficient for identification. Instead, the source must be able to imaginatively reconstruct the negative experiences that the other is undergoing. This is reasonable. Different people sometimes react differently to similar circumstances. Since compassion includes suffering with another and concern for the other's good, it makes sense to require that the other's experiences should be the basis of imaginative identification.

Our modes of epistemological access to the experiences of others are, however, limited. We work primarily by inference and extrapolation. The story is familiar. We have inner, subjective experiences, and behave in recognizable ways when we have them. We observe the similar behavior of others and infer that they have inner experiences similar to ours that correlate with their observable behavior. When we know of another's character, beliefs, and desires, we have a firmer basis for making judgments about the quality of his or her subjective experiences. In short, the better our knowledge of the other, the more likely that our imagination is a reliable guide to the quality of his or her inner life.

This presents a difficulty for attempts by imagination-based accounts to explain compassion for animals. Our modes of access to the inner experiences of nonhuman animals are more restricted than our modes of access to the experiences of fellow humans. Though some forms of animal behavior are similar to human behavior, other differences between species make unlikely consistently reliable inferences from observations of similar behavior to the conclusion of similar subjective experiences. Consequently, if imaginative reconstructions of their subjective states are based on these inferences, imagination is unlikely to be a trustworthy indicator of the nature and quality of their experiences.

Imaginative reconstructions give particularly dubious clues to the inner experiences of animals whose neurophysiology and observable behavior are quite dissimilar from ours. Thomas Nagel goes to the heart of this problem when he writes:

Our own experience provides the basic material for our imagination, whose range is therefore limited.... I want to know what it is like for a bat to be a bat. Yet if I try to imagine this, I am restricted to the resources of my own mind, and those resources are inadequate to the task. I cannot perform it either by imagining additions to my present experience, or by imagining segments gradually subtracted from it, or by imagining some combination of additions, subtractions, and modifications. ${ }^{9}$ [Italics his.]

If imaginative reconstruction of another's subjective experiences is required for compassion, and if our abilities to imaginatively identify with the inner experiences of animals are limited, then it is possible to feel compassion for nonhuman animals on fewer 
occasions than we think. The possibility of compassion on these occasions is premised on our ability to imaginatively enter into the subjective experiences of animals with reasonable accuracy. How might the imagination-based view account for cases in which we think we feel compassion for animals, yet cannot imaginatively reconstruct their inner experiences? One possibility is that we actually experience some other closely related emotion, and have simply misnamed our feeling. The imagination-based account should enable us to identify and explain our error and, also, spur us on to find more nuanced explanations of our emotions toward animals. Another possibility involves departing from the claim that compassion requires imagination. When we lack a firm basis for imaginative identification, yet think we feel compassion-for example, if we think we feel compassion for a bat-our emotion is indeed compassion, but is misplaced or irrational. The appropriateness or rationality of compassion, but not its possibility, would depend on our ability to imaginatively identify with the animal's subjective experiences.

In part III, I argue for different conclusions. When we think we feel compassion for other animals, this usually is what we feel, even when imagination is an unreliable guide to their subjective experiences. (The imagination-based account does not include resources for an "error theory" that could explain why we have apparently mistaken other emotions for compassion.) In addition, compassion for animals is, frequently, neither misplaced nor irrational. Both claims can be substantiated by relinquishing the imagination-based account and turming to the belief-based model of compassion.

\section{I I}

The imagination-based account leads us astray by requiring imaginative identification for compassion. Imagination is not the only way in which identification can be achieved. Other modes of identification are possible. Elsewhere I have claimed:

if $\mathrm{X}$ feels compassion for $\mathrm{Y}, \mathrm{X}$ 's having the following set of true and/or justified beliefs is sufficient for X's compassion for $\mathrm{Y}$ to be rational:

(1) $\mathrm{X}$ must believe that $\mathrm{X}$ or someone close to $X$ is vulnerable and, because of this vulnerability, is susceptible to misfortune;
(2) $\mathrm{X}$ must believe that $\mathrm{X}$ or someone close to $X$ is similar to $Y$ in that $X$ or someone close to $\mathrm{X}$ and $\mathrm{Y}$ are both vulnerable;

(3) X must believe that Y's vulnerability played a part in occasioning Y's misfortune; and

(4) $\mathrm{X}$ must believe that $\mathrm{Y}$ 's misfortune is serious. ${ }^{10}$

$X$ 's having these beliefs is not only sufficient for the rationality of $X$ 's compassion for $Y$, it also allows $X$ to identify with Y's plight. These beliefs make X's compassion for $Y$ possible and rational. The rationality of X's compassion does not depend on X's acknowledging in himself or herself the particular vulnerability believed to occasion Y's misfortune. X need only make the general judgment that he or she is vulnerable, as is $\mathrm{Y}$, and, consequently, can also experience misfortune. ${ }^{11}$

Two challenges must be met if the belief-based account is to provide a convincing alternative to imagination-based attempts to explain compassion for animals. More must be said about how identification can be achieved. ${ }^{12}$ Also, questions about justification must be answered.

Bringing together two ideas helps to clarify identification. One is the distinction between the act of identifying and the content of identification. ${ }^{13}$ The other is the notion that identification is rarely an all-or-nothing affair but, instead, a matter of degree. We are able to identify with others in varying degrees. The different degree of identifiability fall along a continuum, from thinner to thicker. The richer the content, the thicker our identification.

On the Blum/Piper analysis, imagination provides both the act of identifying with the target of compassion and the content of the identification. On the belief-based account, the act of identifying is made possible by the source's having the required beliefs. The beliefs themselves give identification some content. Suppose I believe that you are experiencing a misfortune, for example, a bad presentation of a paper at a professional conference, because of some particular vulnerability, such as the tendency to go blank while speaking before an audience. Since I believe myself to be similarly vulnerable and similarly liable to distress, these beliefs could provide me with a basis for identifying with your plight. Other sources, such as experience and 
imagination, can add content to my belief-based identification. Benevolent other-regarding emotions and attitudes, such as love, friendship, and kinship feelings, can also strengthen our identification with another. They manifest care and concern, and enable us to feel close to others, thereby facilitating identification with those for whom they're felt.

Along the thinner side of the spectrum is the degree of identification needed to have compassion for a bat. Since bats are so dissimilar from humans, the only beliefs likely to make possible an act of identification between source and target are about existential vulnerabilities, that is, the kinds of vulnerabilities, such as susceptibility to sickness and death, that can occasion misfortune for all finite beings. ${ }^{14}$ These beliefs could be the only link between the human person and the bat. In this case, the content of identification is thin indeed. But it need not be so thin. Suppose the source of compassion is a biologist who knows and loves bats. The biologist's specialized knowledge and interest in bats can add content to his or her belief-based identification with the target of emotion.

The belief-based account also faces questions of justification. Many similarities between humans, including similar vulnerabilities, occasion what we usually regard as misfortunes. Beliefs about human weaknesses and their role in occasioning misfortune are not especially hard to justify. Reliable judgments do not require special knowledge or expertise. By contrast, justifying our beliefs about animals can be complicated, since it can require technical knowledge that many people lack. Fewer similarities between human and nonhuman animals than between humans, and less accessible knowledge about actual similarities, can lead to error. We might believe that animals are similar to us when they're different. We could be mistaken about their vulnerabilities, which might be unlike ours. What would be a misfortune for us if we were in their situation might not be unfortunate for them. Lacking the appropriate knowledge of animal biology and behavior, we might not be able to identify what are, for them, true misfortunes.

The key to answering these concerns lies in the realization that compassion for animals is one of several modes of connection between us and them. Compassion and the beliefs about similar vulnerability and similar liability to misfortune that distinguish it are frequently components of a complete network of emotions, values, beliefs, attitudes, and actions that connect us with other beings, describe our relationships with them, and locate our place among other inhabitants in a shared universe. This matrix can, but need not be, sufficiently inclusive and well-developed to be considered a worldview. The rational warrant of compassion as a response to the misfortunes of nonhuman animals depends on the rationality of its distinguishing beliefs. The warrant of both beliefs and, consequently, emotion, depends not just on the extent to which these beliefs accurately reflect the facts of human and animal biology but also on the coherence of compassion and its characteristic beliefs with a conceptual/evaluative framework. A complete justification of compassion for animals should locate the emotion's place within this framework.

This suggests direct and indirect justifications of compassion. The former warrants the emotion by identifying the beliefs characteristic of compassion that furnish the basis of identification between source and target and by justifying these beliefs by showing their fit with facts. Indirect justification affords a different warrant by assuring that compassion coheres with other elements of an inclusive conceptual/evaluative framework. Direct and indirect justifications are not mutually exclusive. Direct is the primary mode of warranting compassion, while indirect is a supplementary form of justification.

An example illustrates direct justification. Suppose a field biologist, studying a gorilla family in their natural habitat, feels what she believes is compassion when a family member dies. Does she feel compassion, or a related emotion? If it is compassion, is it appropriate or rational? To determine whether compassion is felt, we must learn whether there is a basis for identification between biologist and gorillas. Imaginative reconstruction of their subjective experiences could supply a basis for identification. But if she identifies through imagination, it is likely because she believes them similar to her, including being similarly vulnerable to experiencing the death of a loved one. However, if she has these beliefs, which are based on true and/or justified beliefs about similarities between gorilla and human grief, not only can she compassionately identify with their plight, but her emotion is also appropriate and rational, since her beliefs about herself and them are likely justified.

The biologist has expert knowledge that many laypeople lack, and this might bias the example in favor of the belief-based account. Consider another example. Suppose a pet owner, lacking in specialized knowledge 
of animal biology or behavior, feels what she believes is compassion for her cat, whom she believes is ill. Does she really feel compassion, and if so, is her feeling appropriate or rational? Has she a basis for identifying with her pet's plight? She might feel able to imaginatively identify with its subjective experiences. But what if imagination is unreliable? What if the actual differences between her and her cat preclude reliable inferences from the nature and quality of her own subjective states to those of the animal? She might yet be able to identify, if she has the appropriate set of true and/or justified beliefs about herself and her cat. The set would include the beliefs that the cat is weak or vulnerable, that this vulnerability has occasioned some misfortune that the animal experiences, and that she is similar enough to the cat to be similarly vulnerable and, consequently, liable to misfortune. These beliefs could be justified on the basis of the owner's observations of the cat's behavior and its similarities to hers when she experiences distress and on subsequent inferences to the fact that the cat, too, is in distress when displaying similar behavior. However, this kind of inference can be unreliable. It can be strengthened by corroboration from more knowledgeable sources, such as information from a veterinarian.

When an individual's beliefs about the target are not well grounded in a knowledge of facts about animals, indirect justification can supplement direct justification of compassion. Suppose I feel what I believe is compassion for an animal that is significantly dissimilar from humans, such as a bat. Is this emotion really compassion, and could it be rational or appropriate? Is there a basis for identifying with the animal? Imagination is not a likely means of reliable identification, but, unless I have specialized knowledge, neither are my beliefs about the similarities of bats and humans, nor about the vulnerabilities and misfortunes of bats. I might not know how to identify a bona fide misfortune of a bat and, consequently, could falsely believe the animal to be in distress, or fail to spot a true calamity. Despite this potential for error, a bridge between source and target can be laid by my having an appropriate set of beliefs about our similarities with respect to existential vulnerabilities and the misfortunes they occasion. My compassion is warranted provided that these beliefs are true and/or justified.

However, questions arise. Are beliefs about existential vulnerabilities too general to provide a sufficient basis for compassionate identification? Could
I know that my compassion is appropriate or rational without checking my beliefs about the animal's condition against biological facts? Another way of identifying with the bat's plight is given by emotions directed toward a particular animal or generally felt for nature or animals. Love, kinship feelings, and awe or reverence bespeak an attitude of care and concern for other beings. These emotions can forge connections between the source and target of compassion, thereby providing a stronger degree of identification than is achieved only through beliefs. Consequently, compassion is possible even for animals significantly dissimilar from humans.

The appropriateness and rationality of compassion are bolstered by its coherence with other beliefs, emotions, values, and attitudes that connect the source with other beings. The firmer the fit between compassion and other elements of this larger conceptual/ evaluative network, the more rational is compassion. A qualification is needed to accommodate a case in which the entire network, including compassion, is coherent but fails to fit facts. Lacking contact with reality, even a coherent set of beliefs, emotions, values, and attitudes must be judged irrational.

\section{IV}

The previous remarks explain how compassion for animals is possible, appropriate, and rational. To conclude, we can sketch conditions under which compassion is misnamed, misplaced, or irrational.

To misname compassion is to mistake a related emotion for compassion. Both belief and affect are components of emotion. Emotions are identified by referring to distinguishing beliefs. The beliefs characteristic of compassion permit identification between source and target. Other modes of identification are possible. Without the ability to identify with another's plight, a person cannot be moved to compassion, but might mistake for compassion another emotion, such as pity or sympathy.

Compassion is misplaced or inappropriate when its distinguishing beliefs about vulnerability and misfortune are mistaken. Even when these beliefs are not mistaken, compassion can be morally inappropriate. For example, if we believe that Hitler and his followers were sane, it would be morally inappropriate to feel compassion at their demise. This is because we believe them responsible for their deeds, think they ought to have known their 
actions were wrong, and judge they should have felt remorse for their wrongdoing. Similar reasons can render compassion for animals morally inappropriate for members of species where there is evidence of cognitive, emotional, and moral capabilities. ${ }^{15}$

Direct and indirect justification supply two distinct criteria for assessing the rationality of compassion: fit with facts and coherence. Though the rational warrant of compassion is strengthened by coherence, direct justification takes pride of place over indirect. Fit with facts is the ultimate arbiter of the rationality of compassion. Consequently, compassion is irrational if the source persists in feeling it after being made aware of mistaken beliefs about the target's experiences or if the source lacks evidence of the target's misfortune, even if compassion coheres with elements of a more inclusive conceptual/evaluative scheme.

What about a case in which compassion for an animal is rational, since it fits the facts, but fails to cohere with other elements of a conceptual/evaluative network? Suppose a speciesist, despite himself or herself, feels compassion for a suffering animal. In this case, the foregoing analysis has a hopeful implication. If compassion for animals can be and frequently is rational, this is a potentially valuable weapon in arguments against speciesism, since the speciesist is not free to dismiss compassion as merely irrational sentimentality. To be sure, the speciesist could try to revise the emotion to cohere with his or her other beliefs and attitudes. But revision could proceed in the opposite direction. We can hope that the force of rational emotion affords inroads where dispassionate reason alone fails to effect morally constructive changes in outlook.

\section{Notes}

${ }^{1}$ For the imagination-based account, see Lawrence A. Blum, "Compassion," in The Virtues: Contemporary Essays on Moral Character, edited by Robert B. Kruschwitz and Robert C. Roberts (Belmont, CA: Wadsworth Publishing Company, 1987), pp. 229-236; and Adrian M. S. Piper, "Impartiality, Compassion, and Modal Imagination," Ethics vol. 101, no. 4 (July 1991), pp. 726-757. For the belief-based model, see Nancy E. Snow, "Compassion," American Philosophical Quarterly, vol. 28, no. 3 (July 1991), pp. 195-205.

${ }^{2}$ See Snow, p. 197; Blum, pp. 229 and 231, and Piper, p. 743 .

${ }^{3}$ I owe the source/target nomenclature to Lilly-Marlene Russow. See Russow, "How Can We Have Compassion towards Animals?: Comments on Nancy Snow, 'Compassion for Animals," "read at the Society for the Study of Ethics and Animals, Central Division Meeting, Louisville, KY, 24 April 1992, pp. $1-5$.

${ }^{4}$ See Blum, pp. 231-232, and Piper, pp. 740-746.

${ }^{5}$ See Snow, p. 198.

${ }^{6}$ See Snow, p. 196.

${ }^{7}$ Blum, p. 232. Blum has since revised his belief that imaginative identification is required for compassion. See p. 1 of his response to my essay, "Compassion." Both essay and response were read at the Central Division Meeting of the American Philosophical Association, Chicago, IL, April, 1991.

${ }^{8}$ Piper, p. 740.

9 Thomas Nagel, "What is it Like to be a Bat?," in Mortal Questions (Cambridge, England: Cambridge University Press, 1979), p. 169.

${ }^{10}$ Snow, p. 198.

${ }^{11}$ See Snow, p. 199.

12 Russow raises a general problem for the belief-based account of identification. She observes that "trees, paintings, species, and ecosystems, as well as sentient creatures, might be viewed as potential subjects of misfortune." If so, why can't we identify with and feel compassion for trees, paintings, species, and ecosystems? It hardly makes sense to feel compassion for nonsentient beings. The reason is that compassion involves suffering with another, and this implies that the other, with which one suffers, also suffers, that is, subjectively experiences misfortune. But this is too strong. Suppose I know that a close friend has AIDS, but the friend doesn't know it. Can't I feel compassion for him or her, even though he or she doesn't subjectively experience misfortune? Perhaps the capacity to subjectively experience misfortune, rather than the actual subjective experience, is needed for compassion for a being to make sense. This is still too strong for some cases. I have argued that we can and do feel compassion for AIDS babies, anencephalic infants, and the victims of Alzheimer's disease, even though such beings often neither do nor can subjectively experience their misfortunes. (See Snow, pp. 198-199.) I am undecided about the correct analysis of compassion in these cases.

${ }^{13}$ Russow draws this distinction.

${ }^{14}$ See Blum's response, p. 4.

${ }^{15}$ See Donald R. Griffin, Animal Thinking (Cambridge, MA: Harvard University Press, 1984), and Peter Singer, "Animals and the Value of Life," Matters of Life and Death: New Introductory Essays in Moral Philosophy, second edition, edited by Tom Regan (New York, NY: Random House, 1980, 1986), pp. 338-380. 